\title{
Emerging threats in urban ecosystems: a horizon scanning exercise
}

\author{
Margaret C Stanley ${ }^{1 *}$, Jacqueline R Beggs ${ }^{1}$, Imogen E Bassett ${ }^{2}$, Bruce R Burns ${ }^{1}$, Kim N Dirks ${ }^{3}$, Darryl N Jones ${ }^{4}$, \\ Wayne L Linklater ${ }^{5}$, Cate Macinnis- $\mathrm{Ng}^{1}$, Robyn Simcock ${ }^{6}$, Gayle Souter-Brown ${ }^{7}$, Sam A Trowsdale ${ }^{8}$, \\ and Kevin J Gaston ${ }^{9}$
}

As urbanization intensifies, urban ecosystems are increasingly under pressure from a range of threats. Horizon scanning has the potential to act as an early warning system, thereby initiating prompt discussion and decision making about threat mitigation. We undertook a systematic horizon scanning exercise, using a modified Delphi technique and experts from wide-ranging disciplines, to identify emerging threats in urban ecosystems. The 10 identified threats were generally associated with rapid advances in technology (eg solar panels, light-emitting diode lights, self-healing concrete) or with societal demands on urban nature (eg green prescriptions). Although many of the issues identified are also technological opportunities with recognized environmental benefits, we have highlighted emerging risks so that research and mitigation strategies can be initiated promptly. Given the accelerated rate of technological advancement and the increasing demands of urbanized populations, horizon scanning should be conducted routinely for urban ecosystems.

Front Ecol Environ 2015; 13(10): 553-560, doi:10.1890/150229

$\mathrm{U}$ rbanization is predicted to continue, resulting in ongoing and profound physical and biological changes (Pejchar et al. 2015). Biota within urban ecosystems is under pressure from a range of stressors, such as fragmentation, pollutants, and changes in nutrient and water cycles. The mitigation of existing and emerging threats is critical for protecting urban biota and maintaining urban ecosystems (Gaston 2010; Wyse et al. 2015). Urban biota provides ecosystem services - including benefits to human physical and mental health - in addition to

\section{In a nutshell:}

- Early identification and mitigation of threats to the biota of urban ecosystems is important for both people and wildlife

- We conducted a horizon scanning exercise to identify emerging (new and poorly known) threats to urban ecosystems, to facilitate planning and encourage prompt, proactive responses from policy makers and managers

- Among the 10 potential threats identified were risks associated not only with rapid technological advances but also with increasing human demands on nature

${ }^{1}$ Centre for Biodiversity and Biosecurity, School of Biological Sciences, University of Auckland, Auckland, New Zealand *mc.stanley@ auckland.ac.nz); ${ }^{2}$ Auckland Council, Auckland, New Zealand; ${ }^{3}$ School of Population Health, University of Auckland, Auckland, New Zealand; ${ }^{4}$ Environmental Futures Research Institute, Griffith University, Brisbane, Australia; ${ }^{5}$ Centre for Biodiversity and Restoration Ecology, Victoria University, Wellington, New Zealand; ${ }^{6}$ Landcare Research, Auckland, New Zealand; ${ }^{7}$ Greenstone Design UK Ltd, London, UK; ${ }^{8}$ School of Environment, University of Auckland, Auckland, New Zealand; ${ }^{9}$ Environment and Sustainability Institute, University of Exeter, Penryn, UK intrinsic value (Shanahan et al. 2015a, b). However, due to the longevity of hard infrastructure and the multitude of individuals and agencies involved in policy development and decision making, implementing new management strategies to reduce or remove threats to urban ecosystems can be subject to delays that are usually absent from rural or natural areas.

Horizon scanning - the systematic search for potentially important medium- to long-term threats and opportunities within a given discipline (Sutherland and Woodroof 2009; Amanatidou et al. 2012) - can be used to identify potential emerging threats, initiate proactive discussion and decision making, and stimulate threat mitigation efforts. While horizon scanning has been widely implemented in conservation (Sutherland et al. 2011, 2015), it has to date not been applied specifically to urban ecosystems.

Here we performed a horizon scanning exercise, in which workshop participants focused specifically on identifying so-called "emerging" threats - as opposed to exacerbations of current threats - to urban ecosystems. Threats were considered to be emerging if they were not commonly discussed in the scientific literature published in the past 5 to 10 years and/or if they were not proactively dealt with by policy makers or resource managers. Although we limited this horizon scan to target only emerging threats, the technique could be applied more broadly, to include identification of emerging opportunities for enhancing biota and ecosystems in urban centers.

\section{Identification of the threats}

We adopted horizon scanning methods used by Sutherland et al. (2015). This iterative selection process is a modification of the Delphi technique (Figure 1). The 


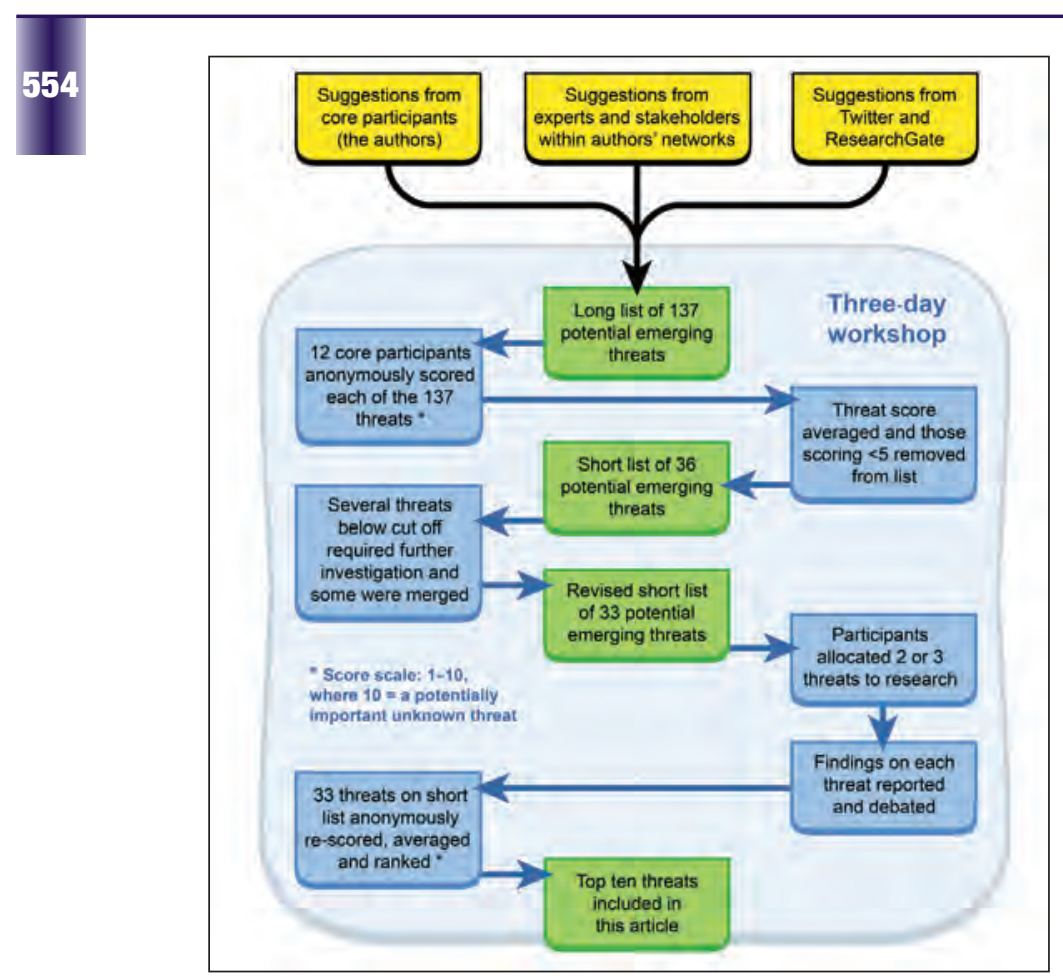

Figure 1. Schematic diagram summarizing the process used to identify and prioritize emerging issues. Broad scoping occurred before the workshop (small yellow boxes). The remainder of the process took place during the 3-day workshop (enclosed in the large blue-shaded box) - small blue boxes indicate author activities whereas small green boxes indicate lists compiled in an iterative process to produce the final 10 emerging threats reported here. See text for further details on the methodological approach.

12 core participants (the authors of this paper) included experts from a range of disciplines relevant to urban ecosystems (ecophysiology, hydrology, ecology, urban design, environmental physics, population health, policy) and were affiliated with science organizations, environmental consultancies, and local government agencies. Each participant consulted other experts and stakeholders from their own professional networks (resulting in $n=$ 124 contributed potential threats from 67 people); we also posed the question "what are the emerging issues and threats in urban environments?" on Twitter $(n=5$ additional contributed potential threats) and ResearchGate ( $n=8$ additional contributed potential threats) and monitored feedback. This consultation resulted in a "long list" of 137 potential threats (Figure 1).

During a 3-day workshop (Figure 1), the core participants individually and anonymously scored each of the 137 potential emerging threats from 1 to 10 (with 10 representing the highest importance). Several of the identified threats were global in scale (eg globalization, climate change) but did not qualify as emerging according to our definition; these existing, well-known threats were likely to worsen or to be exacerbated by other threats (eg fire, drought). Likewise, current human demographic changes (eg aging population, population growth) are likely to exacerbate current threats such as urban intensification.
The scores for the remaining threats were averaged across all participants, and threats with scores below five were removed from the list, leaving 36 threats. Participants identified three potential threats below the score threshold that required further investigation and identified some threats that could be merged, resulting in a final "short list" of 33 threats. Each participant was then allocated 2-3 potential threats to investigate; each threat was assigned to only one participant, who researched its technical details, determined the likelihood of its environmental impact, and assessed how widely the threat was recognized. After reporting their findings to the group for further discussion, participants then anonymously re-scored, averaged, and reranked the 33 threats (on the 1-10 scale as described above). The threats included in this article were the top 10 ranked threats. Their order of presentation, however, reflects the relatedness of the threats, not their ranking.

\section{Emerging threats}

\section{Health-associated demands on green space}

There is a growing body of evidence that connections with nature benefit human health and well-being (Shanahan et al. 2015a, b). At the same time, lifestyle changes have reduced the potential for contact between people and nature (Hartig et al. 2014). Recent innovative health interventions such as "green prescriptions" (written advice and support services given to a patient by a health professional to increase physical activity and/or relieve stress) link nature with health outcomes and encourage greater use of private gardens and public green space (Shanahan et al. 2015a, b). Nevertheless, we argue that a rise in the number of people accessing green space specifically for health benefits, and the promotion of health-related (including exercise) requirements within green space design (SouterBrown 2014), threaten urban ecosystems. Urban green spaces are not sufficient in number or suitably designed for the ever-increasing numbers of users and their associated biota may be imperiled by green space overuse or by redesigns intended to maximize health outcomes.

Localized pressures are likely to negatively affect biota in urban ecosystems. Demands on green space specifically associated with green prescriptions appear to result in extended and formalized navigational routes, enhanced artificial lighting, and flat, highly maintained open spaces for large exercise groups. Alleviation of real and perceived social fears (eg crime) requires the redesign of green space to be more "people friendly" (Figure 2a). This includes subjecting trees to crown lifting or clear stemming, laying artificial turf, and removing understory vegetation to reduce perceived threats to personal safety (Sreetheran and van den Bosch 2014). Similar actions have also been taken in urban residential gardens. Urban biodiversity could deteriorate as more intensive management of vegetation fragments and homogenizes habitat (Ballantyne et al. 2014). Research is required into how to protect the ecology of green space, 

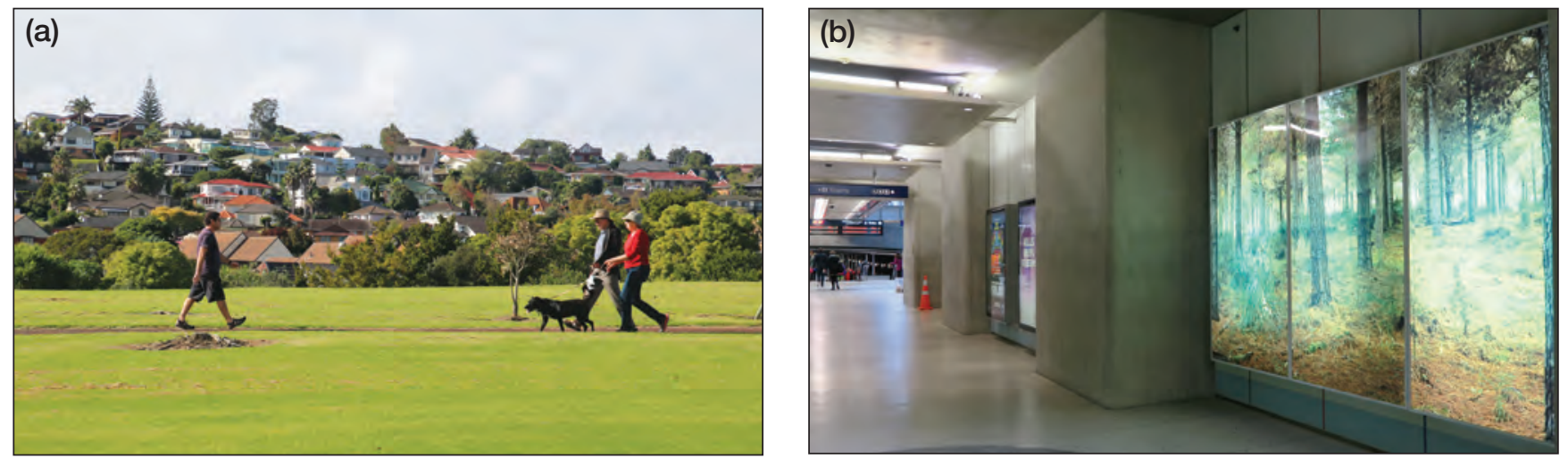

Figure 2. (a) Green spaces used by people for exercise and other health benefits are often fragmented, are highly maintained, and include homogenized habitat with low biodiversity values. (b) Digital mimicry replaces nature inside a train station.

while ensuring it continues to provide the ecosystem services that underpin human health and well-being.

\section{Digital mimicry}

Over the past several decades, the amount of time that city dwellers spend outdoors in close proximity to green space has rapidly declined; simultaneously, there has also been an increase in the prevalence of "Nature Deficit Disorder" (NDD), a range of adverse physical and mental conditions observed in children deprived of interactions with nature (Louv 2005). Although green spaces in urban areas provide opportunities to improve physical and mental health and well-being (Shanahan et al. 2015a), simply having a "green view" has been shown to enhance recuperation and restoration, albeit to a more modest level than engaging directly with green space (Ulrich et al. 1991).

The high quality, low cost, and wide availability of digital mimicry of nature appears to be an attractive alternative remedy for NDD (Figure 2b), given increasing pressure on urban green spaces and the cost of its provision (see previous section). The benefits of exposure to nature appear to be transferrable to a "digital experience", particularly one that includes visual images of and sound recordings from nature (Valtchanov et al. 2010), that can be conveyed cost-effectively in controlled, indoor environments. The digital experience, therefore, avoids less desirable aspects of real-world nature experiences, including possible exposure not only to stinging and biting insects but also to unpleasant or unwanted odors, noise, and sights (including witnessing death and decay). Therefore, we argue that there is a risk of a loss in engaging with and appreciating the value of authentic nature, which could be passed on to subsequent generations as a form of heritable reduction. Such an outcome may prompt a change, whether motivated by politics or economics, whereby preserving and enhancing authentic nature in urban areas (including interior space within buildings) is not prioritized because its benefits can be largely provided digitally. Maintaining a balance between facilitating connections with authentic nature while minimizing any negative consequences of the health-associated demands on green space will be challenging.

\section{Scattered cremains}

Disposal of the solid material resulting from cremation (cremains) is an emerging issue in many urban areas worldwide. In China, where burial has been illegal since 1997 (Figure 3a), physical space for interring cremains is at a premium; in Beijing it can cost up to US\$70 000 per plot (Jiang 2014). As a result, the practice of scattering cremains is becoming more common and is actively promoted in some cities (Figure 3b). For example, the municipal governments in Beijing and Shanghai offer financial incentives for scattering cremains at sea.

The quantity of cremains is prodigious. China alone generates an estimated 12.6 million kilograms of cremains per year, based on a mean of $2.7 \mathrm{~kg}$ per person (Van Deest et al. 2011), a death rate of about 7.11 per 1000 people, and a population of 1.34 billion. In some Asian cities, including Shanghai and Tokyo, almost $100 \%$ of bodies are cremated. Because they are high in phosphate (47\%) and calcium (25\%) (O'Neill nd), cremains - if scattered in sufficient quantities - could exacerbate phosphate enrichment in coastal areas. Global-level thresholds for phosphorus, based on avoiding or minimizing the potential for large-scale ocean anoxic events and eutrophication of freshwater systems, have already been exceeded (Steffen et al. 2015). We suggest that intensive, localized, ongoing input of cremains to both water and land could breach the limits of urban systems. Scattering cremains also puts additional demands on urban green spaces and has already led to conflict in some cities (Vidal 2009; Thompson 2014). We predict that the trend in scattering cremains along with its associated environmental consequences will quickly rise in many cities as an expanding, aging population coincides with reduced space for interment and with growing cultural acceptance of cremation.

\section{Toxoplasma: pet cats as a reservoir for wildlife disease}

Popular companion animals such as domestic cats and dogs, as well as non-traditional pet taxa including turtles, 

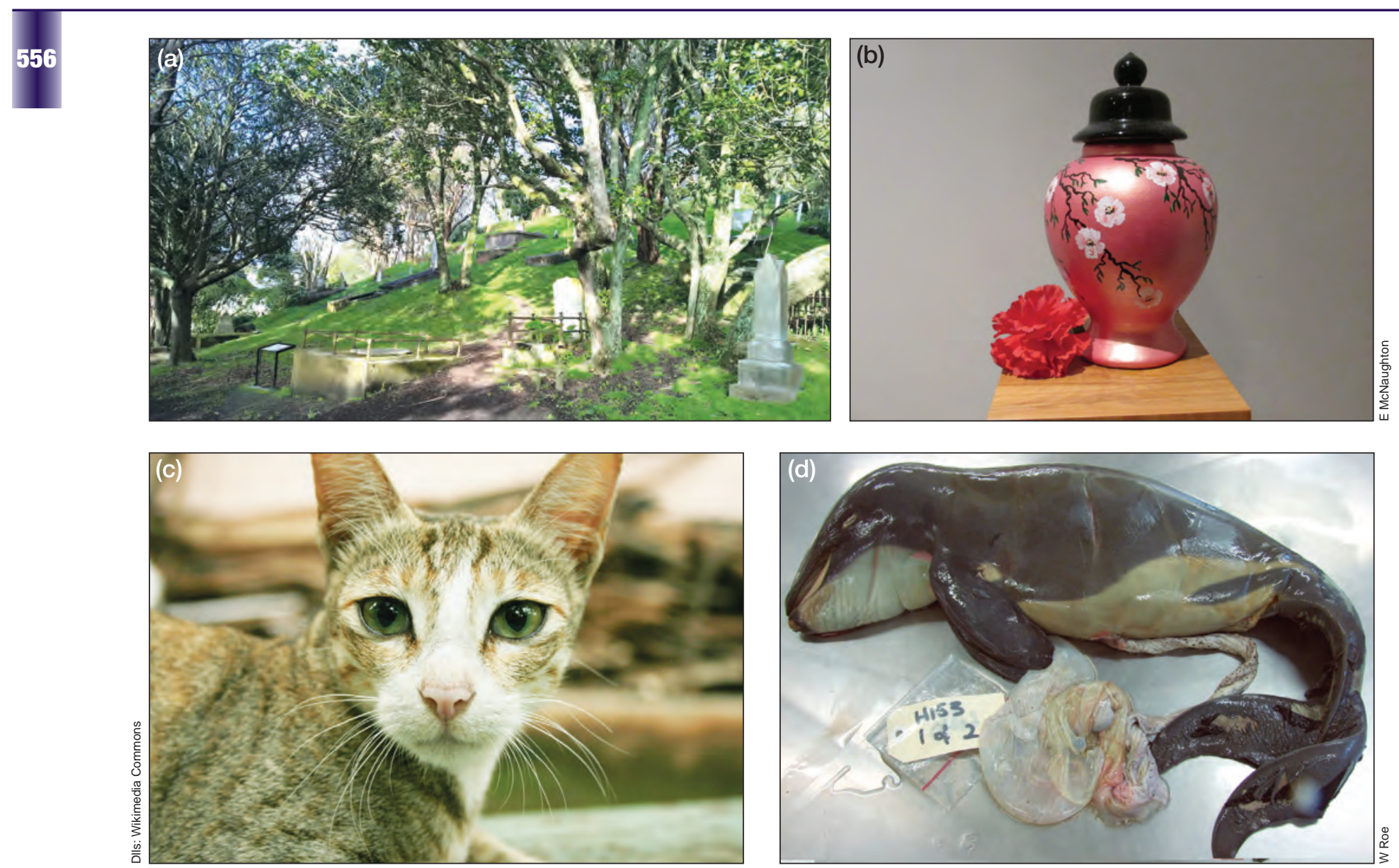

Figure 3. Cultural changes in cities resulting in new potential threats: space limitations in cities resulting in a shift from (a) burial to (b) cremation. Growing urban domestic cat ownership (c) is resulting in the disease toxoplasma spilling over into wildlife populations such as those of the endangered Hector's dolphin Cephalorhynchus hectori $(d)$.

can act as reservoirs for diseases and parasites that can affect sympatric wildlife (eg Riley et al. 2004; Verneau et al. 2011). However, new research highlights the complex and poorly understood ramifications of pet-to-wildlife disease transmission, as illustrated by the growing body of work surrounding toxoplasma. Cats are the definitive host for the protozoan parasite Toxoplasma gondii, but its secondary hosts include a diversity of terrestrial and marine wildlife (eg Dubey et al. 2014). Many Western cities have historically high rates of cat ownership (Figure 3c); pet ownership rates are now also rapidly increasing in the developing world, arguably as a response to increased NDD prevalence, concomitant with urbanization. The global domestic cat population now exceeds 600 million (Peterson et al. 2012). High urban densities facilitate increased disease transmission among cats, and from cats to secondary hosts (Hollings et al. 2013), while population-level impacts of toxoplasma on wildlife remain largely unknown (Figure 3d). Potential mechanisms for such impacts include direct mortality (Roe et al. 2013) as well as reduced reaction times and risk perception, leading to increased predation or roadkill (eg Hollings et al. 2013). Toxoplasma may trophically bioaccumulate, with as yet unknown food-web effects (Hollings et al. 2013). Disease dynamics between domestic cats and wildlife species also require further exploration, given the evidence for multiple pathways of pathogen spillover not only to urban wildlife but also to remote ecosystems such as the Arctic and the marine environment (Roe et al. 2013; Sandström et al. 2013). Responses of naïve hosts in these novel environments should be prioritized for future research.

\section{Uptake of LED nighttime lighting}

Artificial nighttime lighting - including illumination for streets, buildings, advertising, recreational spaces, and vehicles - has long been associated with urbanization. Globally and in most major metropolitan regions, such lighting is dramatically increasing in extent (Hölker et al. 2010; Bennie et al. 2014). The upward emission or reflection of this light can be scattered by the atmosphere, giving rise to skyglow, which markedly extends the area that is lit above ambient levels (commonly over tens to hundreds of kilometers). In almost all its forms, artificial nighttime lighting is poised to undergo a major revolution toward "whiter" spectra, associated with the widespread uptake of light-emitting diodes (LEDs) and emerging light technologies (Figure 4a). This trend is being driven particularly by economic benefits - as compared with traditional lighting technology, LEDs are more 

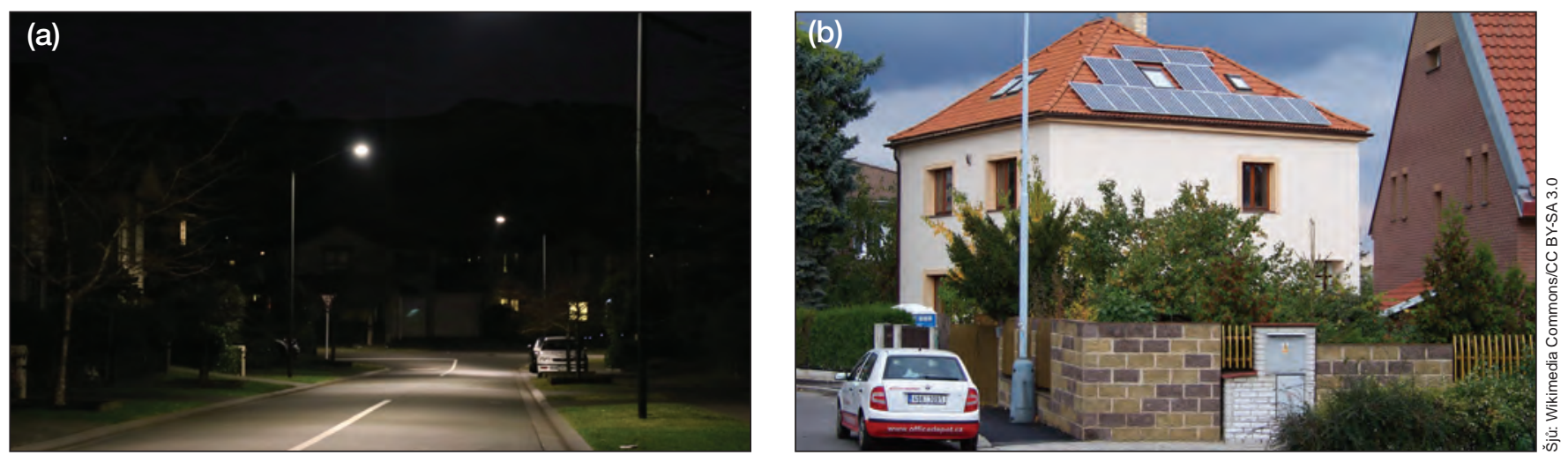

Figure 4. Changes in technology leading to potential impacts on biota: (a) the large-scale uptake of energy efficient LED streetlights; (b) solar panels on roofs in cities could act as ecological traps.

energy efficient, provide high light output with low radiant heat, can distribute light more uniformly (allowing lower levels of lighting), and are dimmable and long lived - but also by the widespread perception that people prefer whiter lighting. This transition will introduce light emissions across a broader range of wavelengths, particularly in the blue parts of the spectrum, and will likely have major ecological impacts. The broadening of the lighting spectrum inevitably means it will overlap with the spectral sensitivities of a wide range of visual and other biological processes (Davies et al. 2013). Moreover, the increase in the emissions in the blue part of the spectrum will exacerbate the skyglow that is detectable by many organisms, will penetrate the water column to a greater extent, will have greater influence on melatonin levels in and circadian rhythms of animal species, and will act as a greater attractor for some organisms (Gaston et al. 2014). Indeed, the transition to whiter lighting could arguably represent the ecologically least favorable change in the spectrum that is possible to conceive.

\section{Solar cities as ecological traps}

The attractiveness of installing photovoltaic cells for solar power has increased in recent years, with falling costs, improved efficiency, and very low emissions and waste streams as compared with other energy technologies (Rogers and Wisland 2014). This is leading to a proliferation in solar panel deployment, with some cities investigating massive installations of photovoltaic cells on city roofscapes and other surfaces (Figure 4b; Beatley 2007). For instance, Seoul, South Korea, is considering the establishment of photovoltaic cells covering 89.5 million square meters of its roofs, to generate $30 \%$ of the city's annual electricity production (Byrne et al. 2015).

Because they polarize light, solar panels - if deployed extensively - could create a massive source of polarized light that might disrupt the behavioral ecology of many species. Many animals rely on polarized light to find suitable habitats, and for orientation and navigation (Horváth et al. 2009). Aquatic insects, in particular, associate polar- ized light with water bodies and are attracted to polarized surfaces that provide opportunities for activities such as oviposition (Horváth et al. 2010). Solar panels can therefore not only act as ecological traps, by attracting animals to sites that are unsuitable for successful reproduction, but also increase predation risk. The cumulative effect of solar panels could substantially reduce the abundance of specific animal populations in cities, with unknown implications for food webs and ecosystems.

\section{Nanotechnology}

Nanotechnology involves the manipulation of matter at a scale of less than 100 nanometers (Bour et al. 2015). Applications are developing rapidly and are highly diverse, including medicine delivery, food packaging, electronics, solar panels, batteries, water filtration, chemical sensors, and the enhancement of fabrics. As such, nanoparticles are becoming ubiquitous and are now an unavoidable but invisible part of urban environments. Because nanoparticles are potentially more toxic than their macro equivalents (due to their large surface area available for ion release), the ecotoxicity of nanoparticles (Navarro et al. 2008) and their harmful effects on humans have become issues of international concern.

Because most nanotechnology is directly associated with human activities, concentrations of nanoparticles will be highest in the built environment. Substances, such as nano-silver, are transported rapidly in aquatic systems and have major impacts on plants, earthworms, and fish (Marambio-Jones and Hoek 2010). However, the effects of nano-silver on other organisms and on entire ecosystems remain unknown. The effects of newer nanoparticles, such as graphene oxide, are also not well understood; one of the few studies on the environmental fate of graphene has shown that the particles are mobile in lakes and streams and are likely to cause negative environmental impacts if released (Lanphere et al. 2014). Investment in graphene industries and their applications (from improved battery life to computer screens) is enormous, with the UK Government and European Union allocating £61 million to establish a National Graphene 

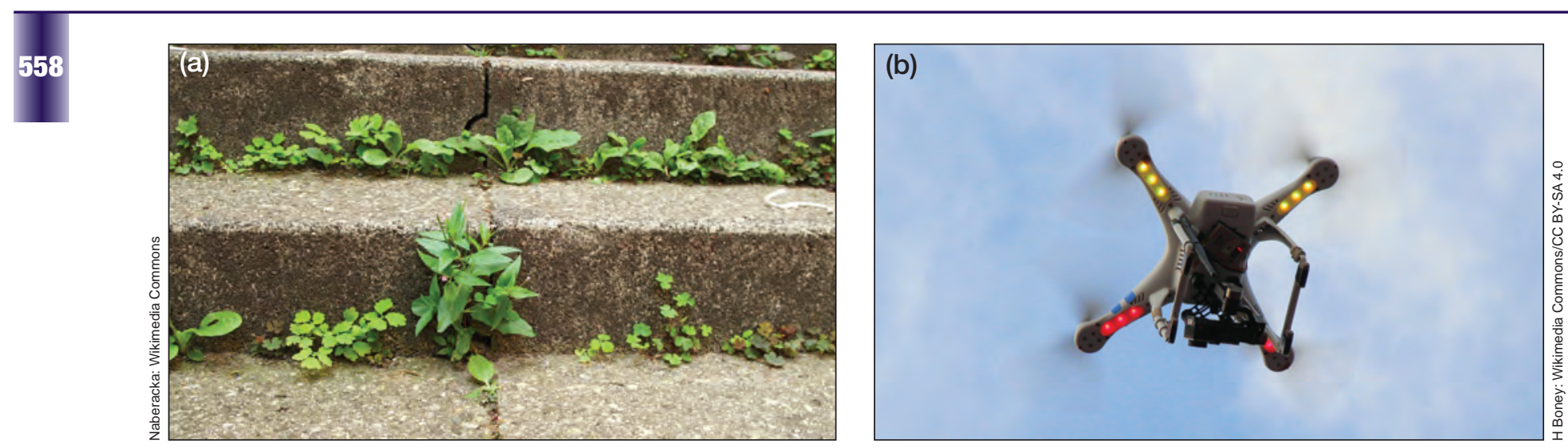

Figure 5. Additional technological advances that may affect urban organisms: (a) self-healing concrete could result in loss of urban biota; (b) the increasing popularity of drones (unmanned aerial vehicles).

Institute at the University of Manchester (Colapinto 2014; www.graphene.manchester.ac.uk).

\section{Self-healing concrete}

As the world's most widely used building material, concrete is pervasive in urban environments. When concrete is exposed to water and chemicals over time, the substance will inevitably crack, which markedly shortens the life span of concrete structures and has led to the incorporation of toxic water-repellent chemicals as a countermeasure. Self-healing concrete is a new material, on the cusp of commercialization, and if successful may become widespread. Infusing concrete with ureolytic bacteria (Bacillus) spores and calcium lactate as a growth medium allows concrete to self-heal as the bacteria grow and precipitate calcium carbonate (Wong 2015).

Cracks in concrete roadways, sidewalks, and walls form one of the most distinctive niches in urban environments. Even in severely degraded urban areas, the microhabitat within these cracks can be rich in resources (such as soil, water, salt, and petroleum products) and can support a diversity of plants (including some of conservation interest; Kantsa et al. 2013), microorganisms, and invertebrates (Figure 5a). Similarly, vegetated facades intentionally installed along exterior walls of buildings support a high diversity of spiders and beetles (Madre et al. 2015). Loss of these vertical and horizontal colonization sites and habitat opportunities with the introduction of selfhealing concrete will decrease urban biodiversity.

\section{Energy-efficient homes}

Although cavities, roof spaces, and walls of residential houses provide shelter as well as breeding and feeding sites for wildlife, particularly bats and cavity-nesting birds (Francis 2010; Russo and Ancillotto 2015), buildings are increasingly made, modified, and managed to achieve consistency and improve sterility in ways that - by design exclude biodiversity (Gunnell et al. 2013). An increasing number of countries are implementing stringent energy efficiency regulations for new houses, while determining how they can improve the energy efficiency of their existing housing stock (World Energy Outlook 2012; Executive Order 13693 2015). For example, in 2006, the UK Government reported that 6.1 million houses lacked adequate loft insulation and 8.5 million houses lacked insulation in cavity walls (Department for Communities and Local Government 2006). Large-scale retrofitting of urban dwellings to improve energy efficiency will likely lead to biodiversity reductions. To achieve greater efficiency, buildings are sealed off from the outside environment, reducing biodiversity by diminishing resource opportunities for organisms (NESCent Working Group on the Evolutionary Biology of the Built Environment et al. 2015).

Partial mitigation can be achieved by retrofitting biodiversity-friendly structures without compromising standards of energy efficiency and building protection (Waring et al. 2012). However, this issue highlights the need for overt solutions during the design phase of construction, so that novel habitat structures can be incorporated into energy efficient modern buildings from the outset.

\section{Drones - unmanned aerial vehicles}

The use of drone technology (unmanned aerial vehicles) for a variety of applications, including emergency responses and goods delivery (Figure 5b), has accelerated rapidly. In the UK alone, 600 commercial companies are registered to use drones (House of Lords 2015). The scale of future proliferation is likely to be massive, with several countries encouraging research and development $(R \& D)$ into robotics and anti-collision software, to take advantage of perceived job creation and increases in economic productivity associated with drone research and use (House of Lords 2015). Amazon.com is investing heavily in R\&D for "within the hour" delivery of $87 \%$ of its goods to customers by drones (Hodson 2014).

The low altitude, noise levels, and prevalence of drones are likely to disturb wildlife, particularly nesting birds (Lambertucci et al. 2015). Some species are especially sensitive to stress, and repeated disturbance may result in interrupted foraging, disrupted sleeping patterns, and nest abandonment or failure. Worryingly, recent research indicates 
that although American black bears (Ursus americanus) do not exhibit any obvious behavioral responses to drone flights, they exhibit a stress response via elevated heart rates (Ditmer et al. 2015). Disturbance impacts are likely to be exacerbated with the widespread use of fleets of simultaneously deployed "swarming" drones, currently being trialed for use in forest fire surveillance (Merino et al. 2012). Moreover, examples have already surfaced of wildlife, particularly raptors, interacting with the drones themselves, primarily during the breeding season (Vas et al. 2015). The need for wide-ranging research evaluating the extent and severity of drone-related disturbance on wildlife is urgent (Vas et al. 2015).

\section{Concluding remarks}

Despite the diversity of emerging threats identified during the horizon scan, common themes included an emphasis on new technologies (eg nanotechnology) and societal demands on nature (eg green prescriptions). The urban environment is particularly vulnerable to emerging threats associated with an accelerated rate of technological advancement, emphasizing the necessity for regularly conducted horizon scans to ensure that such threats are detected early. For instance, changing soundscapes in cities were identified as a potential problem, and we anticipate there will be wider-scale fundamental changes in the acoustic landscape as technology evolves, potentially posing further threats to urban biota (Francis and Barber 2013).

A number of the identified threats relate to changes in cultural practices (eg pet ownership, the disposal of human remains) - which will persist as cities grow, as their residents consume more goods, and as globalization encourages the sharing of cultural trends - and changes in the way people use nature (eg digital mimicry, health-associated demands on green space). Already, there is an emerging paradox, in that city dwellers are increasingly being encouraged to connect with nature in cities and use green spaces, yet increased usage jeopardizes the integrity of the biota in those same green spaces. Clever solutions will be required to mitigate the potential threat to urban ecosystems while maintaining human connections with nature.

Ecological challenges consist of both threats and opportunities. Although our horizon scan focused primarily on threats, several exciting emerging opportunities in urban environments were also identified. For example, the emerging trend to manage urban grassland for biodiversity, including designing grass-free lawns (Smith and Fellowes 2014), is likely to improve ecological outcomes in cities. Furthermore, we did not intend to suggest that the technology associated with some of the identified threats (eg solar panels) be restricted in urban areas, since many of these advances have environmental benefits. We instead concentrated on identifying emerging threats - as opposed to opportunities - in an effort to help mitigate adverse outcomes through research and management before those threats become widespread.

Given the high rate of technological advancement, the increasing demands of populations in urban areas, and the likely cumulative effects of new stressors, horizon scanning should be conducted routinely, to identify emerging threats to urban ecosystems. Iterative horizon scans have great potential to act as catalysts for research to determine the likelihood and magnitude of these possible threats.

\section{Acknowledgements}

The horizon scanning workshop was funded by the Centre for Biodiversity and Biosecurity at the University of Auckland. We thank the many individuals who contributed ideas and issues prior to the workshop.

\section{References}

Amanatidou E, Butter M, Carabias V, et al. 2012. On concepts and methods in horizon scanning: lessons from initiating policy dialogues on emerging issues. Sci Public Pol 39: 208-22.

Ballantyne M, Gudes O, and Pickering CM. 2014. Visitor trails are an important cause of fragmentation in endangered urban forests. Landscape Urban Plan 130: 112-24.

Beatley T. 2007. Envisioning solar cities: urban futures powered by sustainable energy. J Urban Technol 14: 31-46.

Bennie J, Davies TW, Duffy JP, et al. 2014. Contrasting trends in light pollution across Europe. Sci Report 4: 3789.

Bour A, Mouchet J, Silvestre J, et al. 2015. Environmentally relevant approaches to assess nanoparticles ecotoxicology: a review. J Hazard Mater 283: 764-77.

Byrne J, Taminiau J, Kurdgelashvili L, et al. 2015. A review of the solar city concept and methods to assess rooftop solar electric potential, with an illustrative application to the city of Seoul. Renew Sust Energ Rev 41: 830-44.

Colapinto J. 2014. Material question: graphene may be the most remarkable substance ever discovered. But what's it for? New Yorker Magazine. 22 Dec 2014. www.newyorker.com/magazine/2014/12/22/material-question. Viewed 28 Apr 2015.

Davies TW, Bennie J, Inger R, et al. 2013. Artificial light pollution: are shifting spectral signatures changing the balance of species interactions? Glob Change Biol 19: 1417-23.

Department for Communities and Local Government. 2006. Review of sustainability of existing buildings. The energy efficiency of dwellings - initial analysis. London, UK: Department for Communities and Local Government. http://webarchive. nationalarchives.gov.uk/20120919132719/www.communities. gov.uk/publications/planningandbuilding/reviewsustainability. Viewed 23 Apr 2015.

Ditmer MA, Vincent JB, Werden LK, et al. 2015. Bears show a physiological but limited behavioral response to Unmanned Aerial Vehicles. Curr Biol 25: 1-6.

Dubey JP, Van Why K, Verma SK, et al. 2014. Genotyping Toxoplasma gondii from wildlife in Pennsylvania and identification of natural recombinants virulent to mice. Vet Parasitol 200: 74-84.

Executive Order 13693. 2015. Planning for federal sustainability in the next decade. Federal Register 80(57): 15871-84.

Francis CD and Barber JR. 2013. A framework for understanding noise impacts on wildlife: an urgent conservation priority. Front Ecol Environ 11: 305-13.

Francis RA. 2010. Wall ecology: a frontier for urban biodiversity and ecological engineering. Prog Phys Geog 35: 43-63.

Gaston KJ (Ed). 2010. Urban ecology. Cambridge, UK: Cambridge University Press.

Gaston KJ, Duffy JP, Gaston S, et al. 2014. Human alteration of natural light cycles: causes and ecological consequences. Oecologia 176: 917-31. 
Gunnell K, Murphy B, and Williams C. 2013. Designing for biodiversity: a technical guide for new and existing buildings. London, UK: RIBA Publishing.

Hartig T, Mitchell R, De Vries S, and Frumkin H. 2014. Nature and health. Annu Rev Publ Health 35: 207-28.

Hodson H. 2014. Enter the drone zone. New Sci 223: 19-20.

Hölker F, Moss R, Griefahn B, et al. 2010. The dark side of light: a transdisciplinary research agenda for light pollution policy. Ecol Soc 15: 13 .

Hollings T, Jones M, Mooney N, and McCallum H. 2013. Wildlife disease ecology in changing landscapes: mesopredator release and toxoplasmosis. Int J Parasitol 2: 110-18.

Horváth G, Kriska G, Malik P, et al. 2009. Polarized light pollution: a new kind of ecological photopollution. Front Ecol Environ 7: $317-25$.

Horváth G, Blahó M, Egri Á, et al. 2010. Reducing the maladaptive attractiveness of solar panels to polarotactic insects. Conserv Biol 24: 1644-53.

House of Lords. 2015. Civilian use of drones in the EU. EU Select Committee Report. 7th Report of Session 2014-15. HL Paper 122. London, UK: House of Lords Authority.

Jiang C. 2014. A burial plot in Beijing now costs as much as a house in parts of the US. Time (online). http://time.com/1516/ burial-plot-prices-in-beijing. Viewed 4 Feb 2015.

Kantsa A, Tscheulin T, Junker RR, et al. 2013. Urban biodiversity hotspots wait to get discovered: the example of the city of Ioannina, NW Greece. Landscape Urban Plan 120: 129-37.

Lambertucci SA, Shepard ELC, and Wilson RP. 2015. Human-wildlife conflicts in a crowded airspace. Science 348: 502-04.

Lanphere JD, Rogers B, Luth C, et al. 2014. Stability and transport of graphene oxide nanoparticles in groundwater and surface water. Environ Eng Sci 31: 350-59.

Louv R. 2005. Last child in the woods: saving our children from nature deficit disorder. Chapel Hill, NC: Algonquin Books.

Madre F, Clergeau P, Machon N, et al. 2015. Building biodiversity: vegetated façades as habitats for spider and beetle assemblages. Global Ecol Conserv 3: 222-33.

Marambio-Jones C and Hoek EMV. 2010. A review of the antibacterial effects of silver nanomaterials and potential implications for human health and the environment. J Nanoparticle Res 12: 1531-55.

Merino L, Caballero F, Martínez-de-Dios JR, et al. 2012. An unmanned aircraft system for automatic forest fire monitoring and measurement. J Intell Robot Syst 65: 533-48.

Navarro E, Baun A, Behra R, et al. 2008. Environmental behaviour and ecotoxicology of engineered nanoparticles to algae, plants and fungi. Ecotoxicology 17: 372-86.

NESCent Working Group on the Evolutionary Biology of the Built Environment, Martin LJ, Adams RI, et al. 2015. Evolution of the indoor biome. Trends Ecol Evol 30: 223-32.

O'Neill GE. nd. The chemical components of cremated remains. www.lafayettecrematory.com/PublicationsForms/chemicalcomponents.html. Viewed 11 Feb 2015.

Pejchar L, Reed SE, Bixler P, et al. 2015. Consequences of residential development for biodiversity and human well-being. Front Ecol Environ 13: 146-53.

Peterson MN, Hartis B, Rodriguez S, et al. 2012. Opinions from the front lines of cat colony management conflict. PLoS ONE 7: e44616; doi:10.1371/journal.pone.0044616.

Riley SPD, Foley J, and Chomel B. 2004. Exposure to feline and canine pathogens in bobcats and gray foxes in urban and rural zones of a national park in California. J Wildlife Dis 40: 11-22.

Roe WD, Howe L, Baker EJ, et al. 2013. An atypical genotype of Toxoplasma gondii as a cause of mortality in Hector's dolphins (Cephalorhynchus hectori). Vet Parasitol 192: 67-74.

Rogers J and Wisland L. 2014. Solar power on the rise: the technologies and policies behind a booming energy sector. Cambridge, MA: Union of Concerned Scientists.
Russo D and Ancillotto L. 2015. Sensitivity of bats to urbanization: a review. Mamm Biol 80: 205-12.

Sandström CAM, Buma AGJ, Hoye BJ, et al. 2013. Latitudinal variability in the seroprevalence of antibodies against Toxoplasma gondii in non-migrant and Arctic migratory geese. Vet Parasitol 194: 9-15.

Shanahan DF, Lin BB, Bush R, et al. 2015a. Toward improved public health outcomes from urban nature. Am J Public Health 105: 470-77.

Shanahan DF, Fuller RA, Bush R, et al. 2015b. The health benefits of urban nature: how much do we need? BioScience 65: 476-85.

Smith LS and Fellowes MDE. 2014. The grass-free lawn: management and species choice for optimum ground cover and plant diversity. Urban For Urban Gree 13: 433-42.

Souter-Brown G. 2014. Landscape and urban design for health and well-being: using healing, sensory and therapeutic gardens. London, UK: Routledge.

Sreetheran M and Van den Bosch CCK. 2014. A socio-ecological exploration of fear of crime in urban green spaces: a systematic review. Urban For Urban Gree 13: 1-18.

Steffen W, Richardson K, Rockström J, et al. 2015. Planetary boundaries: guiding human development on a changing planet. Science 347; http://dx.doi.org/10.1126/science.1259855.

Sutherland WJ and Woodroof HJ. 2009. The need for environmental horizon scanning. Trends Ecol Evol 24: 523-27.

Sutherland WJ, Clout MN, Depledge M, et al. 2015. A horizon scan of global conservation issues for 2015. Trends Ecol Evol 30: $17-24$.

Sutherland WJ, Fleishman E, Mascia MB, et al. 2011. Methods for collaboratively identifying research priorities and emerging issues in science and policy. Methods Ecol Evol 2: 238-47.

Thompson W. 2014. Bid to limit scatter of ashes. New Zealand Herald. www.nzherald.co.nz/nz/news/article.cfm?c_id=1\& objectid=11267752. Viewed 11 Feb 2015.

Ulrich RS, Simons RF, Losito BD, et al. 1991. Stress recovery during exposure to natural and urban environments. J Environ Psychol 11: 201-30.

Valtchanov D, Barton K, and Ellard C. 2010. Restorative effects of virtual nature settings. Cyberpsychol Behav Soc Netw 13: 503-12.

Van Deest TL, Murad TA, and Bartelink EJ. 2011. A re-examination of cremains weight: sex and age variation in a Northern California sample. J Forensic Sci 56: 344-49.

Vas E, Lescroël A, Duriez O, et al. 2015. Approaching birds with drones: first experiments and ethical guidelines. Biol Lett 11; http://dx.doi.org/10.1098/rsbl.2014.0754.

Verneau O, Palacios C, Platt T, et al. 2011. Invasive species threat: parasite phylogenetics reveals patterns and processes of hostswitching between non-native and native captive freshwater turtles. Parasitol 138: 1778-92.

Vidal J. 2009. Stop scattering ashes, families told. The Guardian. www.theguardian.com/environment/2009/jan/18/cremationsashes. Viewed 11 Feb 2015.

Waring SD, Essah EE, Gunnell K, et al. 2012. Breathable roofing membranes and bats: interactions, outcomes and predictions. Proceedings of the 1st International Conference on Building Sustainability Assessment; 23-25 May 2012; Porto, Portugal. Porto, Portugal: International Initiative for a Sustainable Built Environment.

Wong LS. 2015. Microbial cementation of ureolytic bacteria from the genus Bacillus: a review of the bacterial application on cement-based materials for cleaner production. J Cleaner Prod 93: 5-17.

World Energy Outlook. 2012. Paris, France: International Energy Agency. www.iea.org/publications/freepublications/publication/ world-energy-outlook-2012.html. Viewed 23 Apr 2015.

Wyse SV, Beggs JR, Burns BR, et al. 2015. Protecting trees at an individual level provides insufficient safeguard for urban forests. Landscape Urban Plan 141: 112-22. 